\title{
Study of Heavy Metal Air Pollution, Using a Moss (Grimmia dissimulate) Biomonitoring Technique
}

\author{
T. Gaza*, J. Kugara \\ Department of Chemistry, University of Zimbabwe, Zimbabwe
}

Copyright $\mathrm{C} 2018$ by authors, all rights reserved. Authors agree that this article remains permanently open access under the terms of the Creative Commons Attribution License 4.0 International License

\begin{abstract}
Air pollution is a problem in both developed and developing countries. As a corrective measure, constant air monitoring is usually performed by conventional techniques which are costly and time consuming hence the need for cheaper methods. Recently, biomonitoring has emerged as an effective alternative method. The aim of this study was to investigate heavy metal air pollution in the environment using Mosses. Mosses are lower plants that can provide a surrogate and time-integrated means of measuring elemental depositions from the atmosphere to terrestrial systems. Atmospheric deposition of heavy metals Chromium $(\mathrm{Cr})$, Copper $(\mathrm{Cu})$, lead $(\mathrm{Pb})$, and Zinc $(\mathrm{Zn})$ was studied at the University of Zimbabwe. Moss samples were hung on sites selected by a systematic grid sampling method, during the summer of 2016. The concentrations of heavy metals were determined by Atomic Absorption Spectroscopy (AAS). The concentrations were expressed as Relative Accumulation Factors (RAFs) and the means for $\mathrm{Cr}, \mathrm{Cu}, \mathrm{Pb}$ and $\mathrm{Zn}$ were $14.38 ; 18.17 ; 9.63$ and 10.78 respectively. The results showed the concentration order of deposition was $\mathrm{Cu}>\mathrm{Cr}>$ $\mathrm{Zn}>\mathrm{Pb}$ and that $\mathrm{Zn}$ deposited uniformly as evidenced by its low sample variance which was more than 17 and 56 times smaller than that of $\mathrm{Pb}$ and $\mathrm{Cr}-\mathrm{Cu}$ respectively. Although the distribution patterns of $\mathrm{Cr}$ and $\mathrm{Cu}$ were similar, $\mathrm{Pb}$ and $\mathrm{Zn}$ had their own patterns. The results suggested that the source of heavy metal could be from traffic related air pollutants.
\end{abstract}

Keywords Air Quality, Heavy Metals, Moss Biomonitoring, Relative Accumulation Factors, GIS Technology, Low-cost, Equipment, Time-consuming

\section{Introduction}

Uncontaminated air is a fundamental requisite of human health and well-being [1]. Air pollution however continues to be a serious problem in many parts of the world, particularly in developing countries [2]. According to the World Health Organization, more than two million premature deaths can be attributed to the effects of air pollution annually and more than half of these are from populations in developing countries [3]. The considerable contribution of air pollution to the diminished health status of exposed human populations, compromised integrity of ecosystems, forest decline, loss of agricultural productivity, and many others has been a reason for increased public concern throughout the whole world. Subsequently, it is crucial to persistently evaluate and monitor the levels of heavy metals in the environment, for evaluation of human exposure and for sustainable environment [4].

Atmospheric pollutants exist as a wide array of environmental contaminants; which may be of either natural or anthropogenic origin. Amongst these pollutants, are heavy metals and other toxic elements which usually exist in association with Air-borne Particulate Matter. From literature, there are two conceptual approaches for taking field measurements relevant for atmospheric deposition and air pollution related studies that emerge clearly. These are the use of instrumental monitoring devices and use of suitable air pollution biomonitors. The first approach requires sampling on a continuous basis at a large number of sites, in order to ensure spatial representativeness of measurements. The application of such measurements on a large scale is expensive and person-power intensive [5]. It is here that, the second approach is considered because it is non-expensive and yet provides a reliable way of carrying out air quality status assessment in a country or a region [2].

Biomonitoring can be defined as the act of continuously observing a geographical area with the help of living organisms such as, plants, or animals, to obtain information on environmental quality over space and time, that is, the response of living organisms to changes in their environment(e.g. by their elemental content) [2]. These organisms when employed, integrate pollution over time, thereby reducing the need for continuous chemical monitoring, thus avoiding the difficulty of interpreting 
"snapshot" measurements and presenting a potential for retrospective monitoring. Such organisms enrich themselves with substance to be determined, thereby improving analytical accessibility as well as reducing uncertainty of measurement. By observing and measuring the changes in an appropriately selected organism, a conclusion as to the kind of pollution, its source and its intensity can be drawn [2].

Botanically, mosses are bryophytes. Two Swedish scientists ÅkeRühling and Germund Tyler (1960) discovered that mosses are good biomonitors of heavy metal pollution in the atmosphere. Mosses possess many properties that make them suitable for monitoring air pollutants [6]. These species obtain nutrients from wet and dry deposition because they do not have real roots so there is no uptake of mineral substrates from other sources except the atmosphere. Nutrient uptake from the atmosphere is promoted by their weakly developed cuticle (so metal ions easily penetrate the cell wall) and large surface to weight ratio. Other suitable properties include a slow growth rate, small size and easy to handle, undeveloped vascular bundles (so transport of minerals between segments is limited), minimal morphological changes during the mosses' lifetime, perenniality, wide distribution (even in industrial and urban areas), an ability to survive in highly polluted environment, ease of sampling and the possibility to determine concentrations in the annual growth segments [7].

The "moss bag technique" involves exposure of moss samples held within mesh bags in order to monitor the presence of contaminants in the air. The technique is mainly used to monitor atmospheric levels of contaminants such as metals, metalloids, nitrogen, sulphur, ozone, radionuclides and more recently polycyclic aromatic hydrocarbons $(\mathrm{PAH})$.

In developing countries, air pollution problems are amplified by increased rural to urban migration, industrialization and the rapid growth of fueled transportation systems in-line with population growth [8]. In Africa the problems are further compounded by poor urban planning and the importation of second hand vehicles [9].

In Zimbabwe, the presence of heavy metals in the air has been previously investigated but the studies were limited by low spatial representativeness of measurements, mainly because of the prohibitively high costs of instrumental devices. The primary task of this paper was to study the present atmospheric air pollution status, in the sampling area, using a bio-monitoring technique by exploiting its capability to be operated at high spatial resolution, over longer periods of time without the need for power and at low costs.

\section{Materials and Methods}

\subsection{Study Area}

The study was conducted at the University of Zimbabwe main campus, which is located in the Northern region of the City of Harare. It lies between latitudes $-17.7790^{\circ} \mathrm{N}$ and $-17.792^{\circ} \mathrm{N}$ and longitudes $31.0430^{\circ} \mathrm{E}$ and $31.065^{\circ} \mathrm{E}$ as is shown in Figure 1. Harare is the capital city of the Republic of Zimbabwe and it has a sub-tropical climate. The annual average temperature is about $18.4^{\circ} \mathrm{C}$, the hottest month is October, with an average temperature of $28.8^{\circ} \mathrm{C}$ and the average annual rainfall is about $865 \mathrm{~mm}$. The bio-monitoring survey was conducted from the 1 st of March to 29th April, 2016. During the experimental period, the average daily air temperature was $22.5^{\circ} \mathrm{C}$, the prevailing wind direction was NW, the average daily wind speed was $2 \mathrm{~m} \mathrm{~s}^{-1}$ and the average relative air humidity and total rainfall were $78 \%$ and $15 \mathrm{~mm}$, respectively (UZ Dept of Geography and Environmental sciences, 2016).

\subsection{Moss Bag Preparation}

At the beginning of February 2016, Moss Grimmia dissimulate (Figure 2) was collected from a pristine area located in the Mukuvisi Woodlands in Harare. This site was chosen on the basis that it is in a nature reserve and hence is presumed to be less influenced by anthropogenic activities known to be prevalent outside its bounds. In the laboratory, the green apical portion of the mosses were separated from the rest and manually cleaned of soil particles, plant remains and epiphytes $[10,11]$. Subsequently, the moss was rinsed with double distilled water. It was then, air-dried and gently hand-mixed to obtain a homogeneous sample.

Approximately $10.0 \mathrm{~g}$ of the moss was packed loosely into polythene net bags (about $5 \mathrm{~cm}$ across) with a $5-\mathrm{mm}$ mesh size, resulting in a surface area of approximately 30

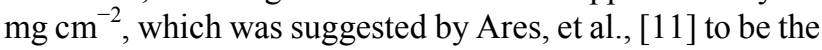
most suitable for maximum uptake. To avoid contamination of the moss material, the entire process of moss sampling and bag preparation was conducted while wearing polyethylene powder-free gloves. Several moss bags were sealed in air tight plastic bags and stored in a refrigerator at $4^{\circ} \mathrm{C}$ as control samples for the determination of the initial pollutant concentrations. The moss bags were mounted on wooden poles, and this enabled the covering of any microenvironment of interest, such as roads, residential-housing areas, sports fields, etc. The moss bags were placed at a representative height of $2-3 \mathrm{~m}[11]$ in open spaces far from tree canopies, roofs and electric cables. The sites were uniformly positioned across the study area to represent all land use classes. 


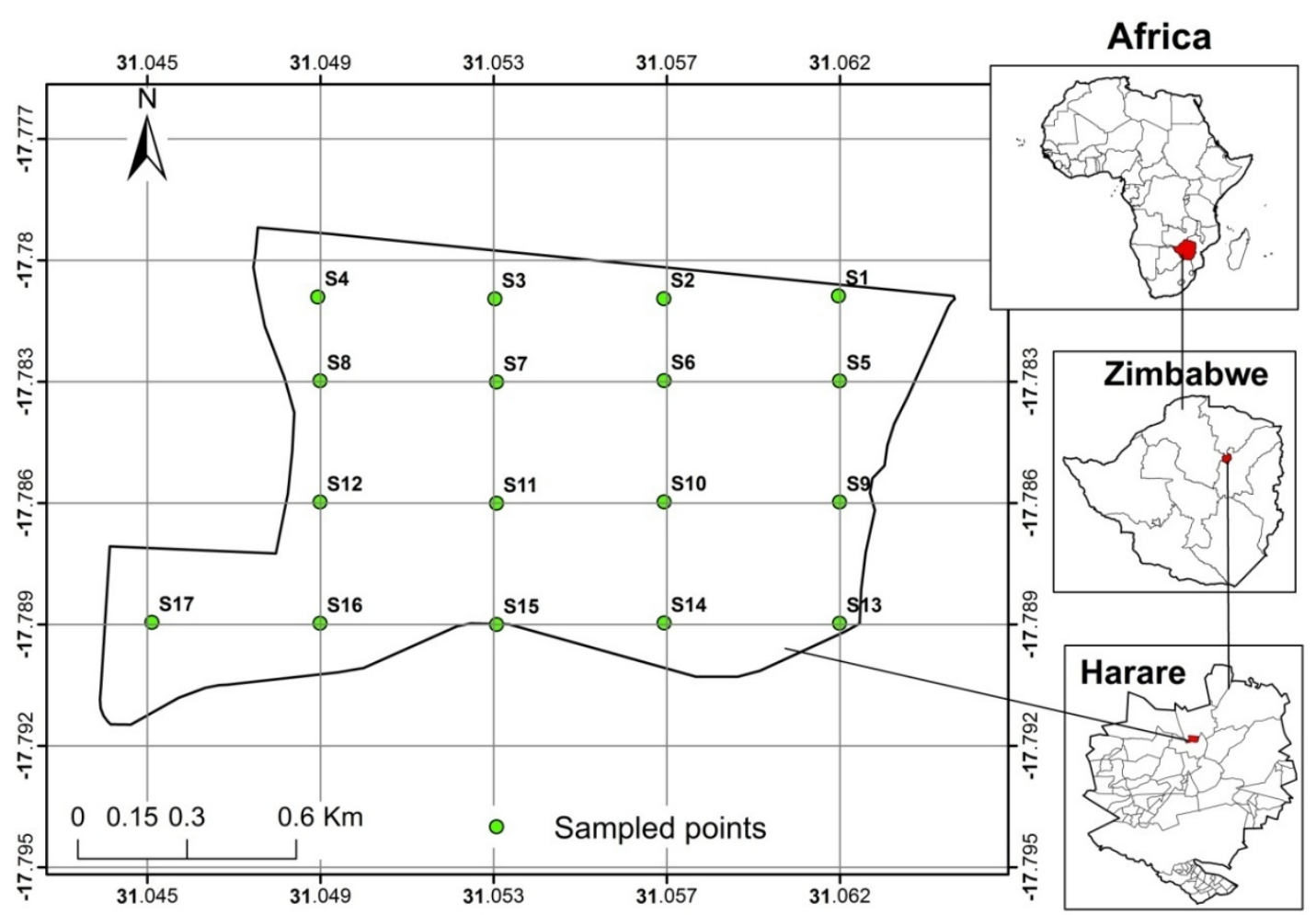

Figure 1. Location of the study site

\subsection{Sampling}

To identify spatial variations in air pollution throughout the study area, 17 sampling sites were chosen uniformly to cover the study area (Figure 1). The entire territory was divided into a regular grid of $450 \mathrm{~m} \times 350 \mathrm{~m}$ with sampling sites located at the corners of each rectangle and their geographical coordinates determined by a GPS devise (GARMIN GPS 62SC). Each site was formed by collecting three sub samples located within an area of $20 \times 20 \mathrm{~m}^{2}$. In the field, certain sampling sites were relocated to avoid unusable locations, such as buildings, construction sites, sport fields, tree plantations and rivers. The moss samples were collected using polyethylene gloves so as to prevent any further sample contamination. The collected material was stored in plastic bags. All of the collected samples were cleaned from extraneous material (litter and dead leaves) and dried to constant weight for $48 \mathrm{hrs}$ at $40^{\circ} \mathrm{C}$. Unwashed green and green-brown parts of the moss stems corresponding to 3 years of the moss growth were prepared for analysis [12].

\subsection{Sample Preparation}

Each of the three sub samples were combined to come up with one composite sample. The composite sample was then ground to fine powder in a mortar and pestle. Then about $5.0 \mathrm{~g}$ of each composite sample were transferred into digestion flasks. Concentrated $\mathrm{HNO}_{3}$ and $\mathrm{HCl}$ were added to each flask in the ratio 3:1 and the mixture heated. After digestion, the solution was allowed to cool and then filtered through Whatman filter paper and the volume of the filtrate was made up to $20 \mathrm{ml}$ with deionized water [13]; [14]. The metal contents in the filtrates $(\mathrm{Cr}, \mathrm{Cu}, \mathrm{Pb}$ and $\mathrm{Zn})$ were determined using Atomic Absorption Spectrophotometry.

\subsection{Reagents and Standards}

For this study, reagents of analytical grade were used and deionised water was used for the preparation of all solutions.

\subsection{Preparation of Standard Solution}

$1000 \mathrm{ppm}$ Stock solutions were purchased from Merck South Africa and then diluted as required.

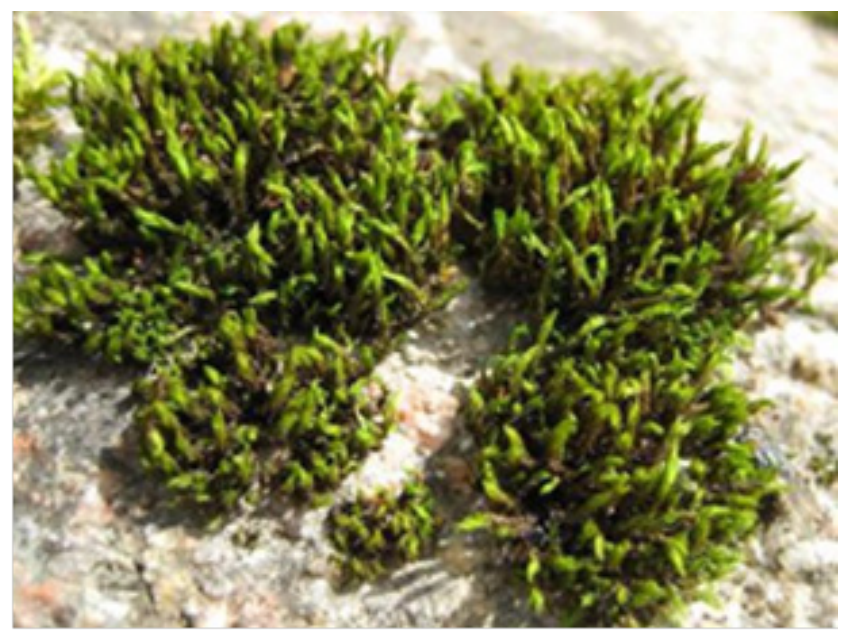

Figure 2. Grimmia dissimulate 


\subsection{Instrumentation}

Atomic Absorption Spectrophotometry was used for the analysis of the heavy metals (Shimadzu, AA-6701F).

\subsection{Data Processing}

To assess the elemental accumulation of the studied moss species, Relative Accumulation Factors (RAFs) were calculated based on the moss content of each element after exposure $\left(\mathrm{C}_{\text {exposed }}\right)$ subtracted and then divided by the element content before exposure $\left(\mathrm{C}_{\text {initial }}\right)$ as is shown in below:

$$
\mathrm{RAF}=\frac{C_{\text {exposed }}-C_{\text {initial }}}{C_{\text {initial }}}
$$

The data were processed using Microsoft Office 2007 and all maps were made using ArcGIS 9.3. Universal kriging with the linear variogram interpolation method was applied for the construction of maps showing the spatial distribution of heavy metals in moss samples. IBM SPSS version 21 was used for statistical calculations.

Table 1. Description and geographic coordinates of the sampling sites

\begin{tabular}{|c|c|c|}
\hline Sampling site & Description of Sampling site & Geographic coordinates \\
\hline $\mathrm{S} 1$ & Major Road & $-17.7810 \mathrm{~N}, 31.0570 \mathrm{E}$ \\
\hline $\mathrm{S} 2$ & Commuter Omnibus Station & $-17.7810 \mathrm{~N}, 31.0570 \mathrm{E}$ \\
\hline $\mathrm{S} 3$ & Car Park & $-17.7810 \mathrm{~N}, 31.0530 \mathrm{E}$ \\
\hline S4 & Close To Car A Park & $-17.7810 \mathrm{~N}, 31.0490 \mathrm{E}$ \\
\hline S5 & Minor Road & $-17.7830 \mathrm{~N}, 31.0620 \mathrm{E}$ \\
\hline S6 & In Between Buildings & $-17.7830 \mathrm{~N}, 31.0570 \mathrm{E}$ \\
\hline S7 & Car Park & $-17.7830 \mathrm{~N}, 31.0530 \mathrm{E}$ \\
\hline S8 & In Between Buildings & $-17.7830 \mathrm{~N}, 31.0490 \mathrm{E}$ \\
\hline S9 & Close To A Major Road & $-17.7860 \mathrm{~N}, 31.0620 \mathrm{E}$ \\
\hline $\mathrm{S} 10$ & Open Field & $-17.7860 \mathrm{~N}, 31.0570 \mathrm{E}$ \\
\hline $\mathrm{S} 11$ & Sports Arena & $-17.7860 \mathrm{~N}, 31.0530 \mathrm{E}$ \\
\hline S12 & In Between Buildings & $-17.7860 \mathrm{~N}, 31.0490 \mathrm{E}$ \\
\hline $\mathrm{S} 13$ & Close To A Major Cross Road & $-17.7890 \mathrm{~N}, 31.0620 \mathrm{E}$ \\
\hline $\mathrm{S} 14$ & Open Field & $-17.7890 \mathrm{~N}, 31.0570 \mathrm{E}$ \\
\hline $\mathrm{S} 15$ & Major Road & $-17.7890 \mathrm{~N}, 31.0530 \mathrm{E}$ \\
\hline $\mathrm{S} 16$ & Minor Road & $-17.7890 \mathrm{~N}, 31.0490 \mathrm{E}$ \\
\hline $\mathrm{S} 17$ & Close To A Major Road & $-17.7890 \mathrm{~N}, 31.0450 \mathrm{E}$ \\
\hline
\end{tabular}

Table 2. Instrumentation and operating conditions for the Atomic absorption System

\begin{tabular}{|c|c|c|c|c|}
\hline Parameter & $\mathrm{Cr}$ & $\mathrm{Cu}$ & $\mathrm{Pb}$ & $\mathrm{Zn}$ \\
\hline Wavelength $/ \mathrm{nm}$ & 358 & 324.8 & 283.3 & 213.7 \\
\hline Spectral Width slit $/ \mathrm{nm}$ & 0.5 & 0.5 & 0.5 & 0.5 \\
\hline Lamp current $/ \mathrm{mA}$ & 10 & 6 & 10 & 8 \\
\hline
\end{tabular}

\section{Results and Discussion}

\subsection{Quantitative Descriptions}

\subsubsection{Descriptive Statistics}

A total of 4 elements were analyzed by application of Atomic Absorption Spectrophotometry. The descriptive statistics are shown in Table 4. To test for the normality of the data, the Shapiro-Wilk test was performed on the data set [15]. Based on the results (Table 3) it can be noted that, the RAFs of all the metals were normally distributed except for $\mathrm{Zn}$ and this was at statistical significance $(\mathrm{P}>0.05)$. This was further confirmed by the skewness value for $\mathrm{Zn}$ from Table 4 which was -1.17 . Usually for data to be considered as being normal, its skewness must be in the range -0.8 to 0.8 and its kurtosis in the range of -3.0 to 3 [16].

Table 3. Test of normality

\begin{tabular}{|c|c|c|c|}
\hline \multirow{2}{*}{} & \multicolumn{3}{|c|}{ Shapiro-Wilk } \\
\cline { 2 - 4 } & Statistic & df & Sig. \\
\hline $\mathrm{Cr}$ & .947 & 17 & .411 \\
\hline $\mathrm{Cu}$ & .923 & 17 & .166 \\
\hline $\mathrm{Pb}$ & .949 & 17 & .436 \\
\hline $\mathrm{Zn}$ & .790 & 17 & .001 \\
\hline *. This is a lower bound of the true significance.
\end{tabular}


The mean RAFs from Table 4 were compared and arranged in decreasing order of magnitude as shown in Figure 3. A clear order emerges as follows; $\mathrm{Cu}>\mathrm{Cr}>\mathrm{Zn}>\mathrm{Pb}$. Therefore $\mathrm{Cu}$ can be described as having been the most polluting and $\mathrm{Pb}$ the least polluting.

Table 4. Descriptive statistics of RAFs

\begin{tabular}{|c|c|c|c|c|}
\hline Parameter & $\mathrm{Cr}$ & $\mathrm{Cu}$ & $\mathrm{Pb}$ & $\mathrm{Zn}$ \\
\hline & & & & \\
\hline Mean & 14.38 & 18.14 & 9.63 & 10.78 \\
\hline Standard Error & 2.36 & 2.52 & 1.35 & 0.33 \\
\hline Median & 13.95 & 15.59 & 9.42 & 11.30 \\
\hline Standard Deviation & 9.73 & 10.37 & 5.57 & 1.34 \\
\hline Sample Variance & 94.70 & 107.54 & 31.07 & 1.80 \\
\hline Kurtosis & -0.68 & -1.30 & 0.73 & -0.13 \\
\hline Skewness & 0.50 & 0.29 & 0.67 & -1.17 \\
\hline Range & 31.90 & 31.62 & 21.34 & 4.07 \\
\hline Minimum & 0.78 & 4.75 & 1.55 & 7.93 \\
\hline Maximum & 32.68 & 36.37 & 22.89 & 12.00 \\
\hline Sum & 244.43 & 308.32 & 163.64 & 183.22 \\
\hline Count & 17 & 17 & 17 & 17 \\
\hline
\end{tabular}

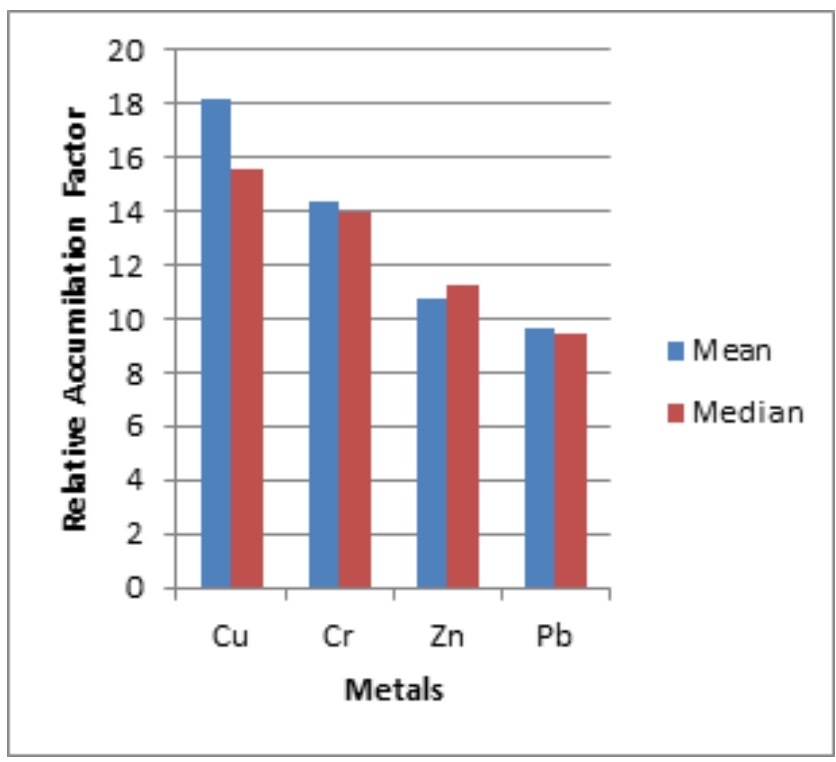

Figure 3. The mean and median values of the RAFs Distributions of Heavy Metals

The distribution patterns of the 4 metals analysed are shown in Figure 4. By visual inspection it can be noted that they all have similar patterns which is also be confirmed by the positive correlation co-efficients shown in Table 5. Although they have similar patterns, on closer analysis of the spread, it can be noted that $\mathrm{Zn}$ had very little spread such that when compared to the other 3 metals, it approximates a straight line. The same trend can be picked up by analysing the sample variances shown in Table 4 . The sample variances of $\mathrm{Cr}$ and $\mathrm{Cu}$ are almost the same $(94.70 \approx 107.54)$ and hence can be treated as one. $\mathrm{Pb}$ has a variance value of 31.07 , which is about 3 times smaller, when compared to that of $\mathrm{Cr}-\mathrm{Cu}$. But that of $\mathrm{Zn}$ is about 15 smaller than that of $\mathrm{Pb}$. So $\mathrm{Zn}$ can be described as having deposited in almost equal amounts throughout the study area hence the low spread.

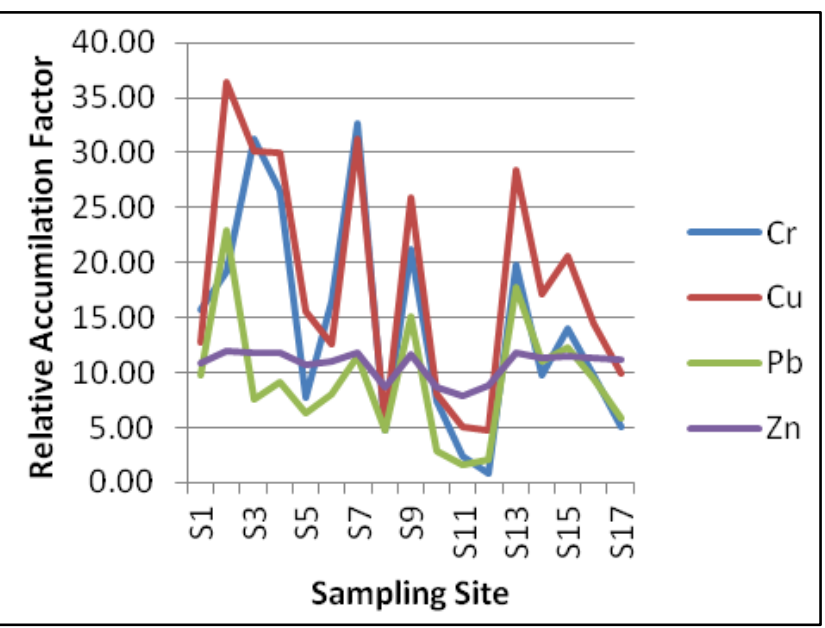

Figure 4. Comparison of distribution patterns between metals.

In an effort to further describe the 4 distributions, cluster analysis, using the hierarchical method was applied. The results are shown in a dendrogram in Figure 5. The results show that the 4 distributions can be put into 3 different categories, the first having $\mathrm{Cr}$ and $\mathrm{Cu}$ (which are almost similar), the second having $\mathrm{Pb}$ and the third one having $\mathrm{Zn}$. However the distribution of $\mathrm{Pb}$ shows some resemblance to those of $\mathrm{Cr}$ and $\mathrm{Cu}$ more than it does to that of $\mathrm{Zn}$. Thus, since $\mathrm{Cr}$ and $\mathrm{Cu}$ have almost similar distribution patterns, they can be described as having deposited in an almost the same manner while $\mathrm{Pb}$ and $\mathrm{Zn}$ deposited in their own fashions, though that of $\mathrm{Pb}$ was somewhat similar to that of $\mathrm{Cr}$ and $\mathrm{Cu}$. 


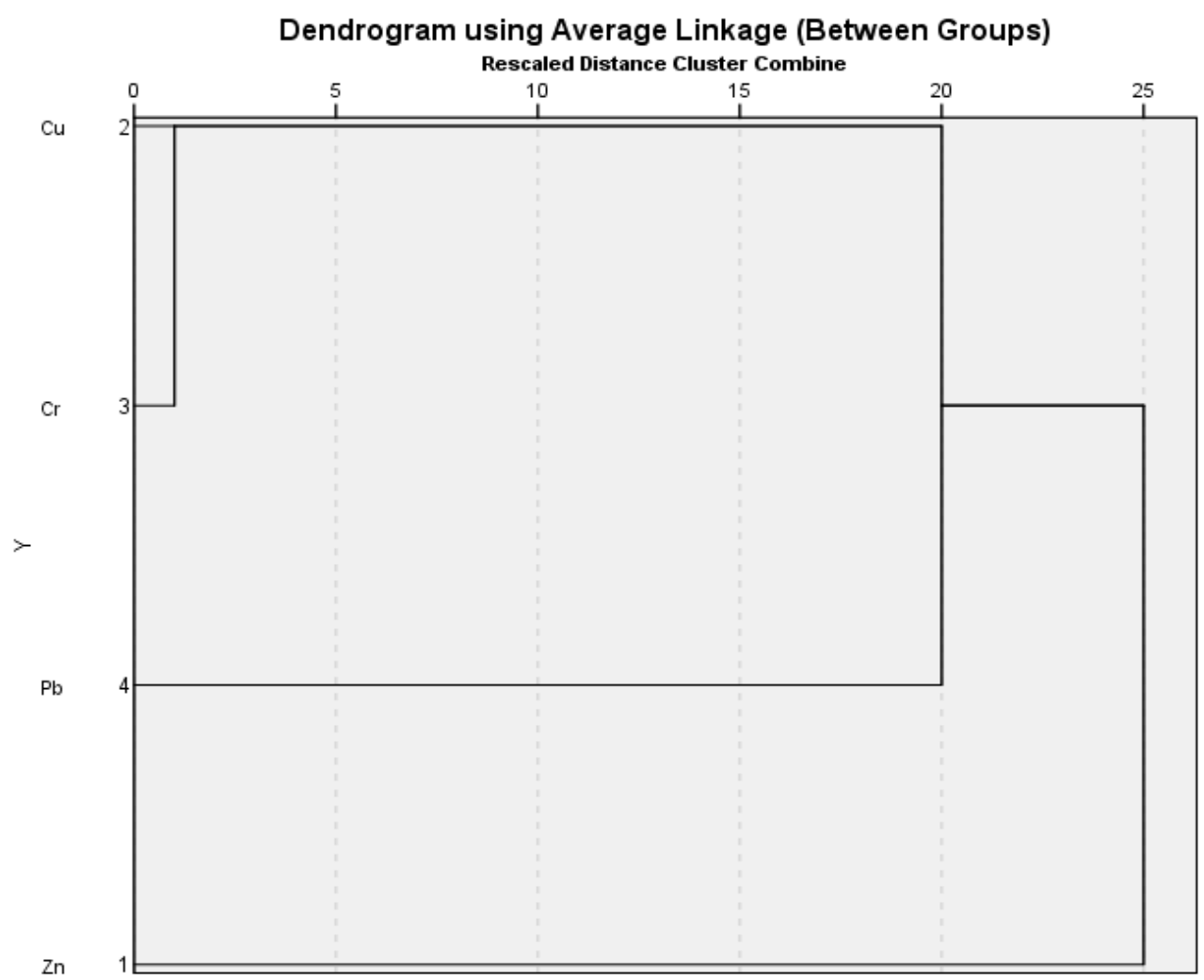

Figure 5. Dendrogram showing clustering of the heavy metal distributions

\subsection{Spatial Distribution of the Elements}

GIS maps were plotted to show the spatial distribution of the elements.

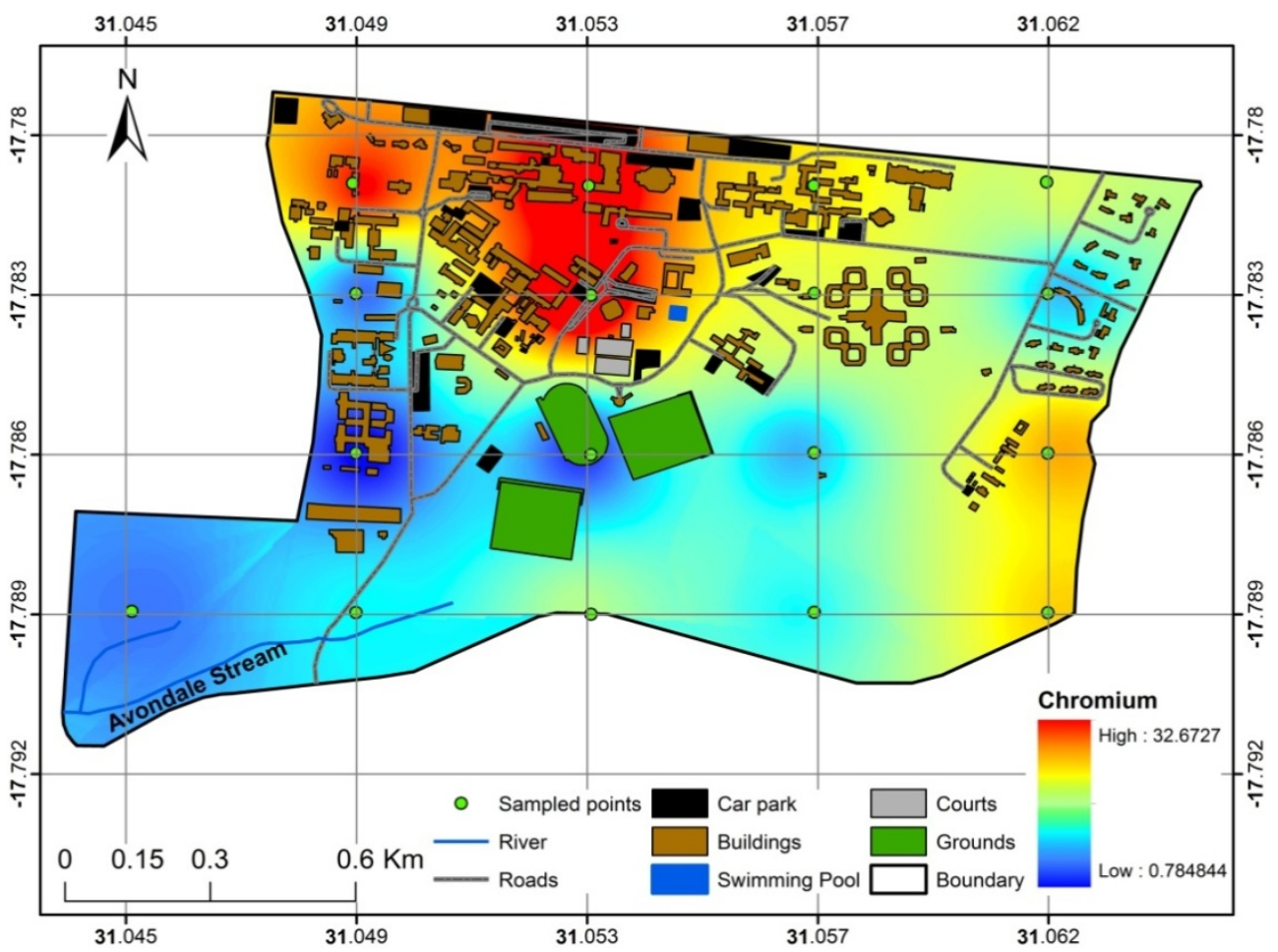

Figure 6. Spatial distribution map Chromium deposition based on moss content 


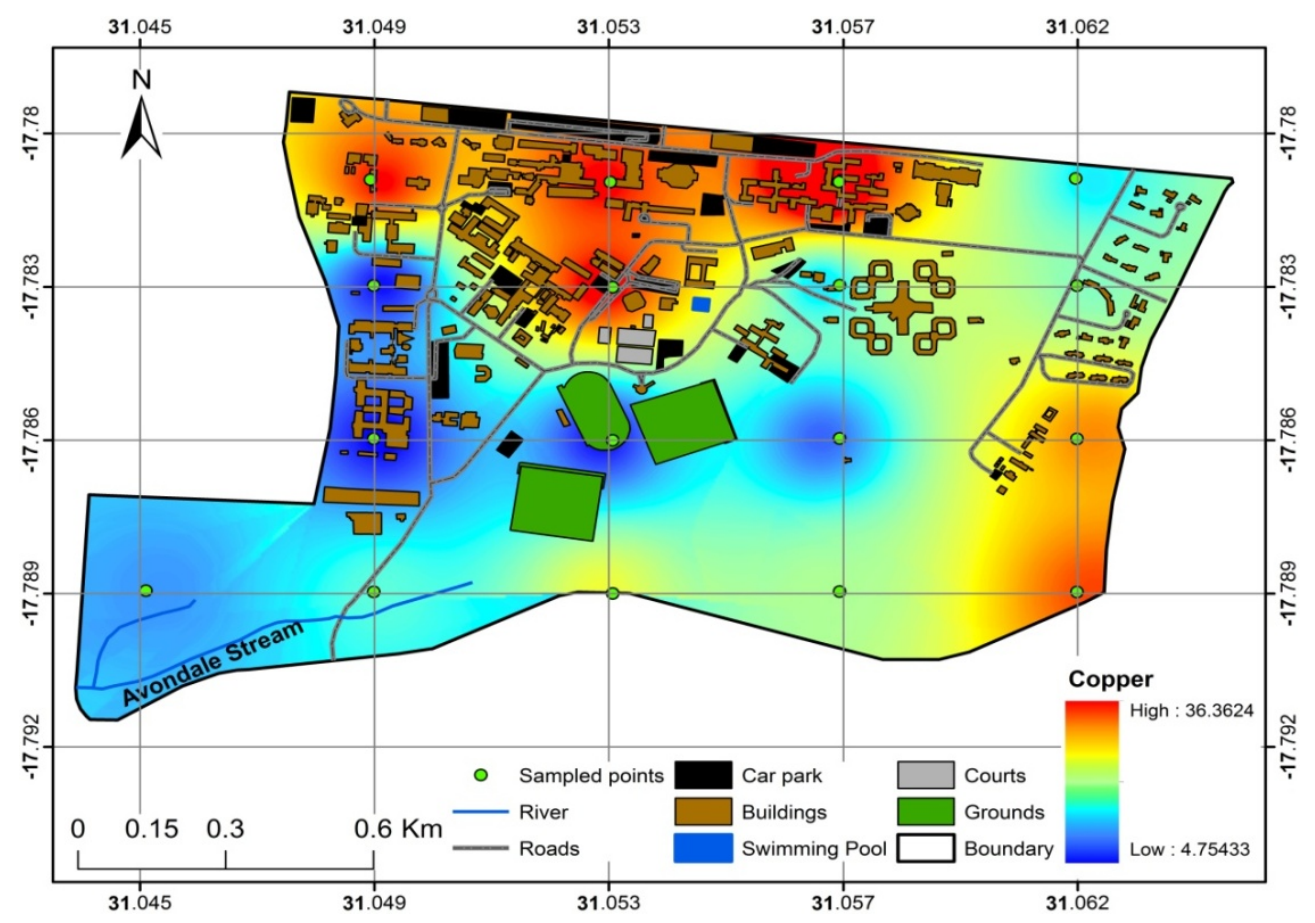

Figure 7. Spatial distribution map Copper deposition based on moss content

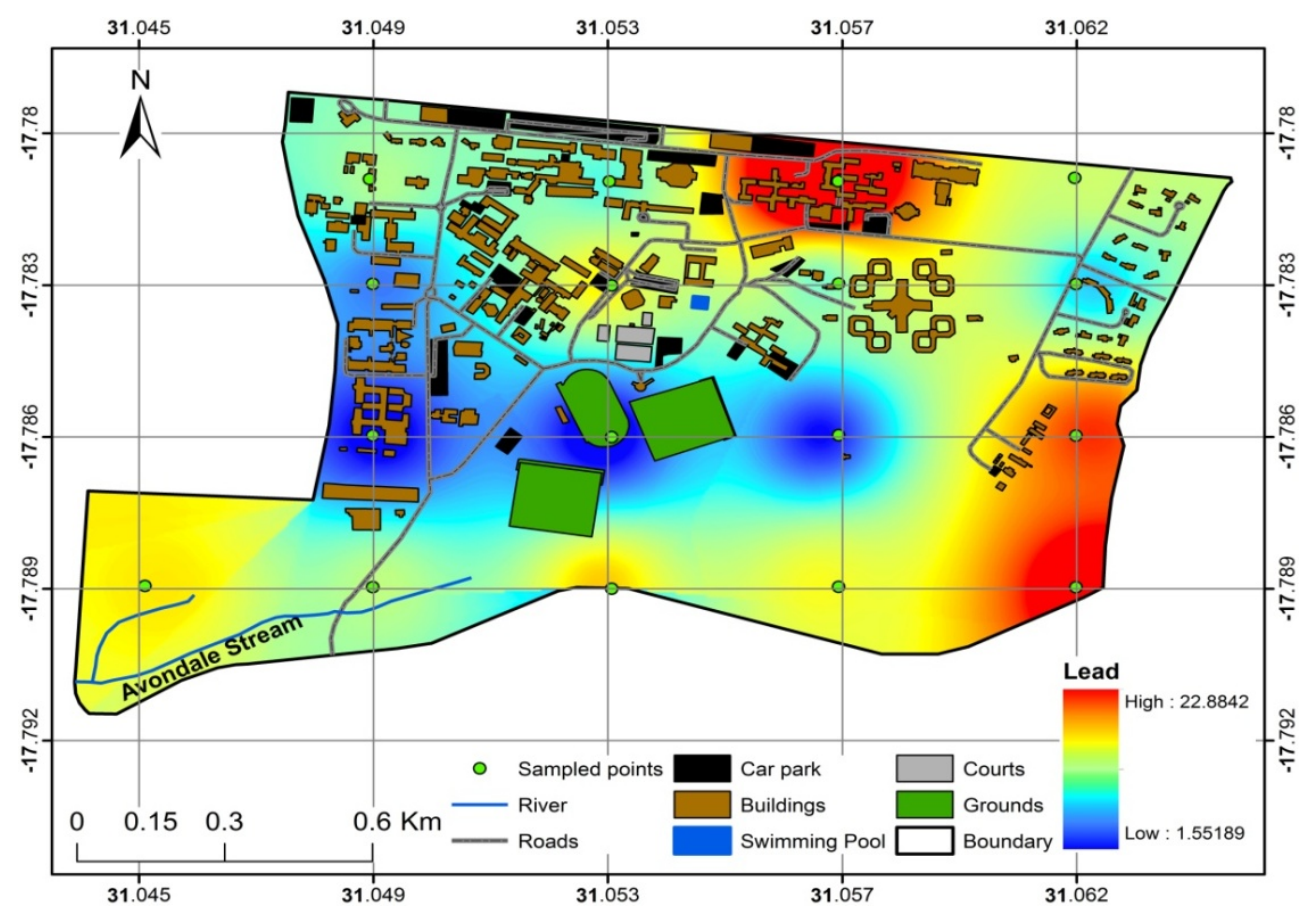

Figure 8. Spatial distribution map Lead deposition based on moss content 


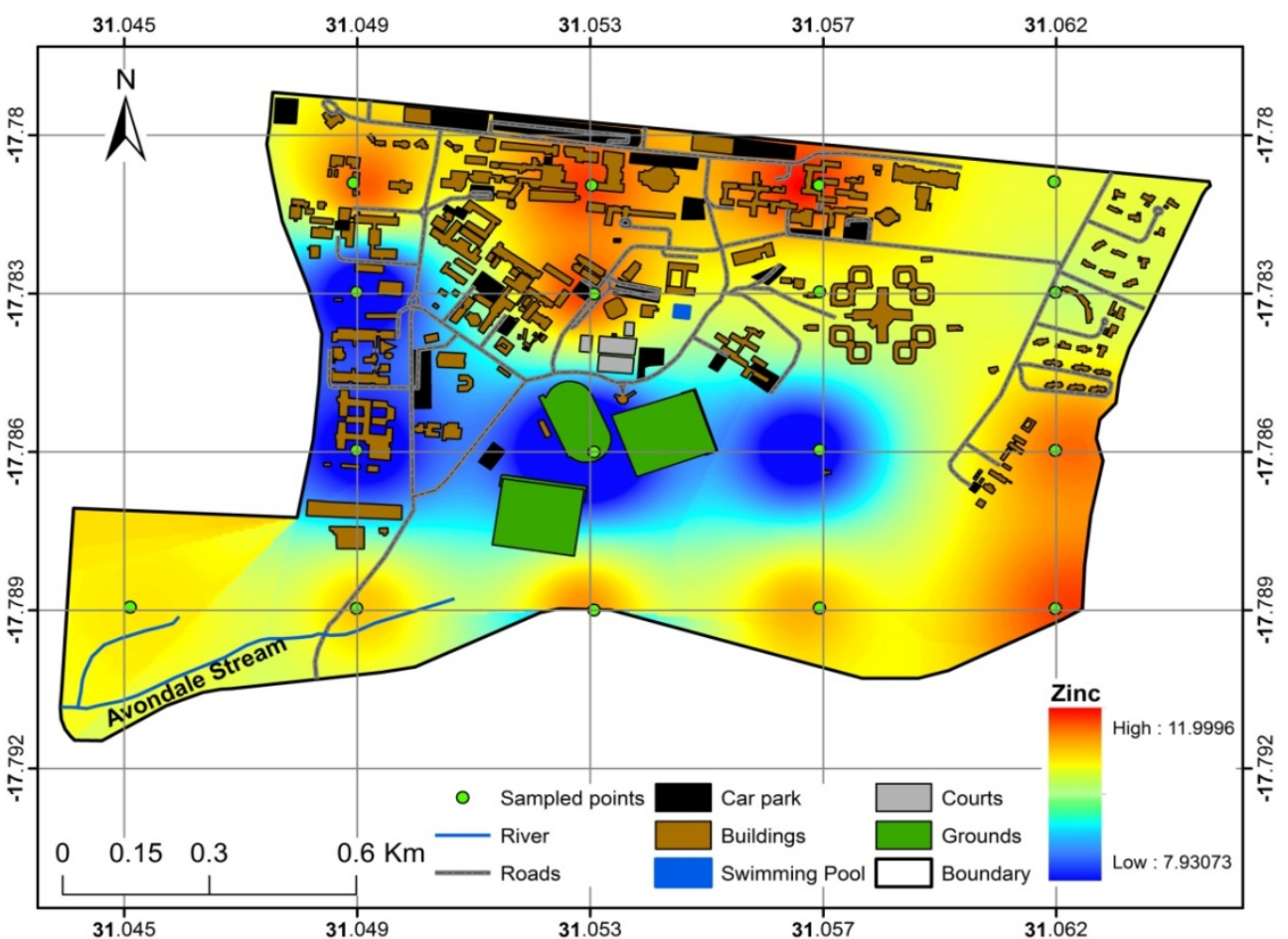

Figure 9. Spatial distribution map Zinc deposition based on moss content

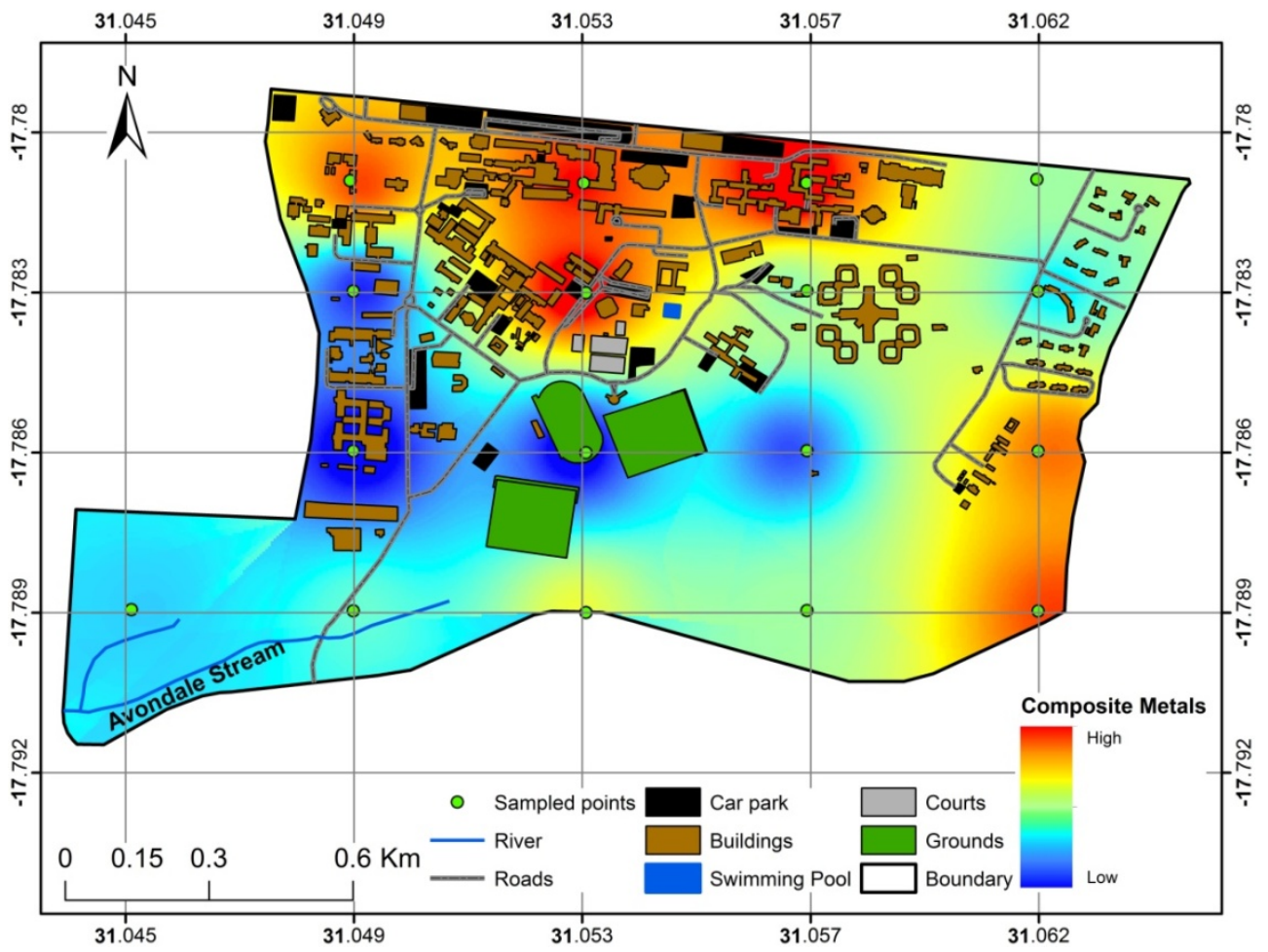

Figure 10. Spatial distribution maps of Total heavy Metal Deposition based on moss content 


\subsection{Different Zones of Heavy Metal Air Pollution}

Cluster analysis was performed on the data set in order to determine the number of different zones of pollution that existed per each spatial distribution and further classify the data into appropriate zones. The resulting dendrograms (Figure 6 to Figure 9) were in strong agreement with their respective Spatial Distribution Maps (SDM). The results suggested that for $\mathrm{Cr}, \mathrm{Cu}$, and $\mathrm{Pb}, 3$ zones existed and for $\mathrm{Zn}$ only 2 . The three clusters that emerge from the $\mathrm{Cr}, \mathrm{Cu}$, and $\mathrm{Pb}$ dendrograms were described as cold spots, mild spots and hot spots. For Zn, which had only 2 zones, the zones were described as polluted and unpolluted.

\subsubsection{Chromium Heavy Metal Air Pollution Zones}

The first cluster to emerge from the $\mathrm{Cr}$ dendrogram (Figure 11) consists of points S14, S16, S5, S10, S8, S17, $\mathrm{S} 11$ and S12. When read with reference to the SDM of $\mathrm{Cr}$ in Figure 4.13, it can be noted that this group consists of points with the lowest RAFs of $\mathrm{Cr}$ and hence denote the $\mathrm{Cr}$ cold spots. This cluster can be further subdivided into two other sub clusters. These were termed the high cold spots, consisting of points S14, S16, S5 and S10 and the other cluster the low cold spots consisting of points S8, S17, S11, and S12. This low cold spot cluster can be described as the pristine region for $\mathrm{Cr}$.

The second cluster to emerge consists of points S2, S13, S9, S1, S6 and S15. This was described as the mild cluster. It can further be sub divided into two sub groups one with points S2, S13 and S9, which are on the high side of mild and the other with points S1, S6 and S15 which are on the lower side of mild.

The third cluster to emerge consists of points S3, S7 and S4. These are the hot spots for Cr. Points S3 and S7 are red hot spots on the high side while point S4 is a hot spot on the low side.

\subsubsection{Copper Heavy Metal Air Pollution Clusters}

Applying the same analysis used for $\mathrm{Cr}$ above, for $\mathrm{Cu}$ the first cluster to emerge consists of points S8, S11, S12, S10 and S17. This cluster denotes the cold spots. It can be divided into two subgroups one consisting of points S8, S11 and S12 and the other group of points S10 and S17. The first sub group consisting of points S8, S11and S12 this can be described as the pristine regions for copper.

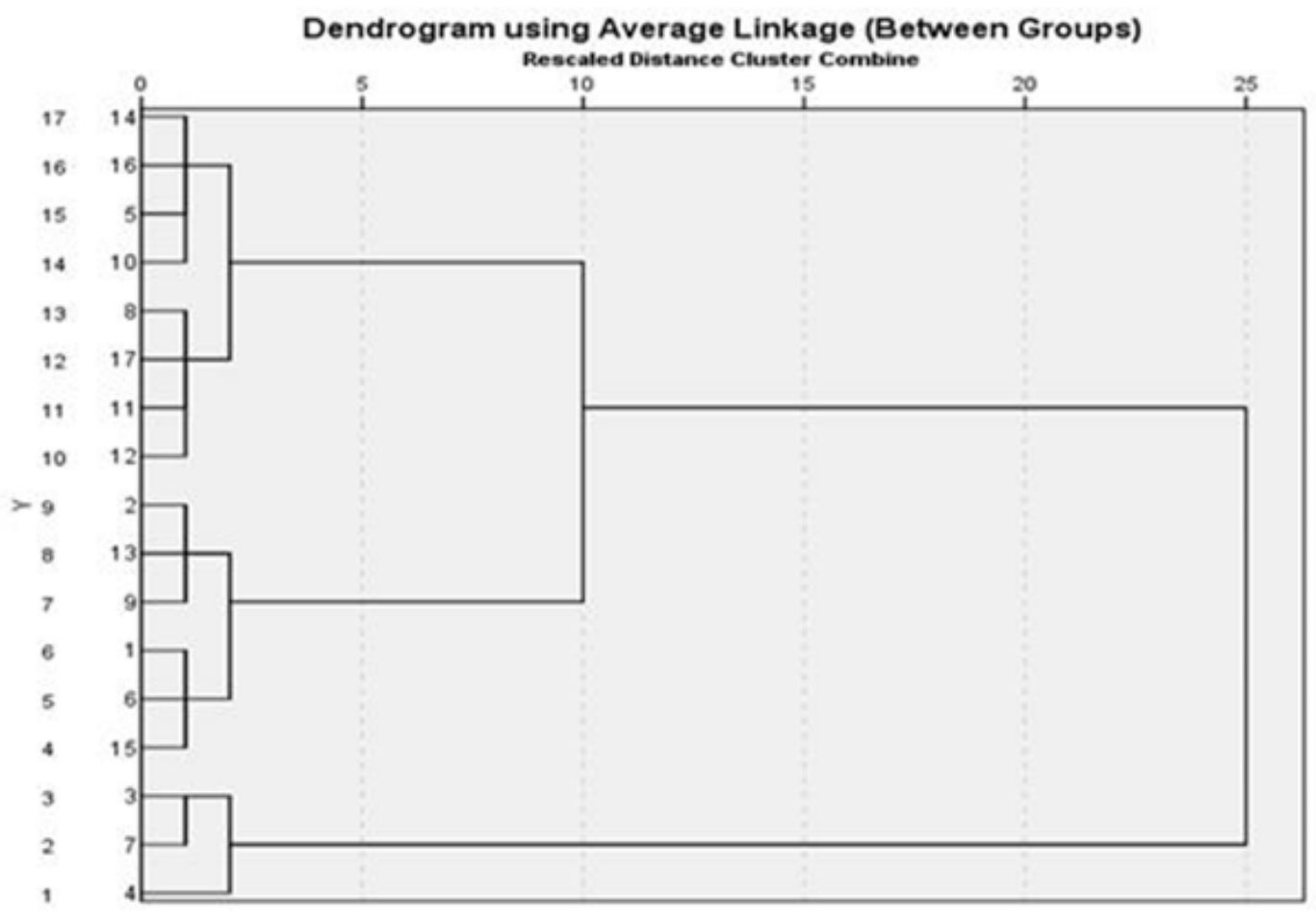

Figure 11. Dendrogram showing clustering of analysed chromium sampling sites 


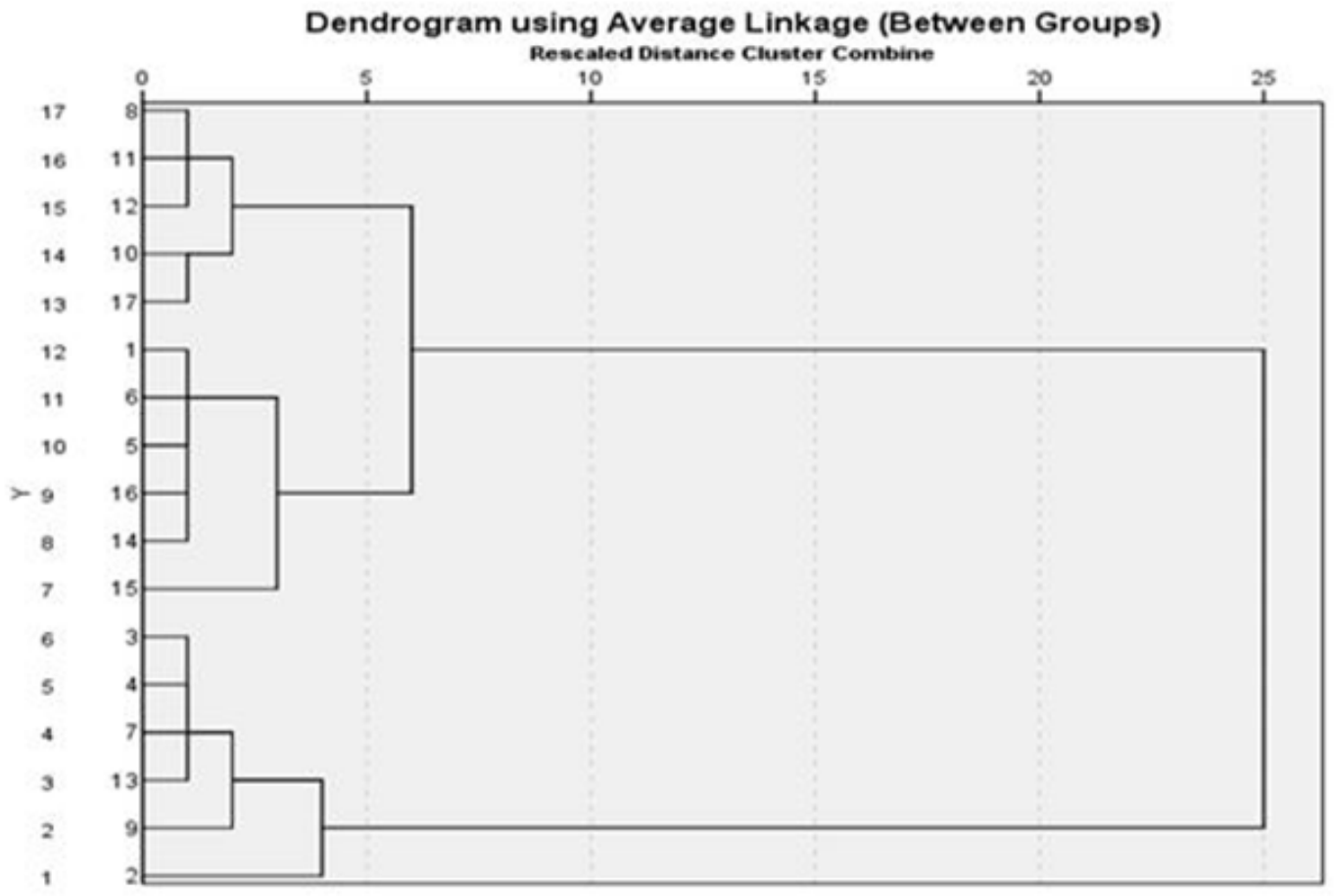

Figure 12. Dendrogram showing clustering of analysed copper sampling sites

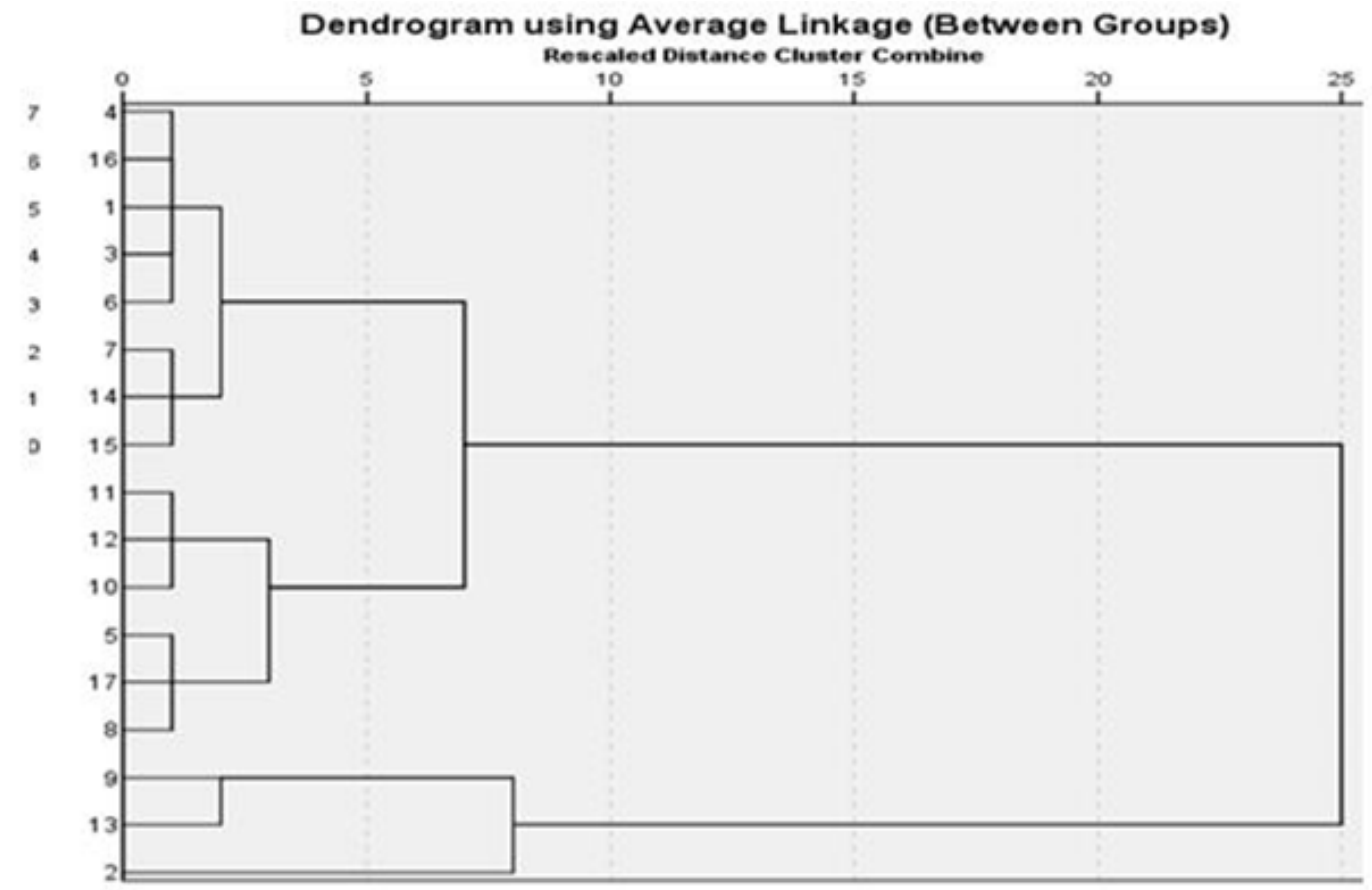

Figure 13. Dendrogram showing clustering of analysed lead sampling sites 


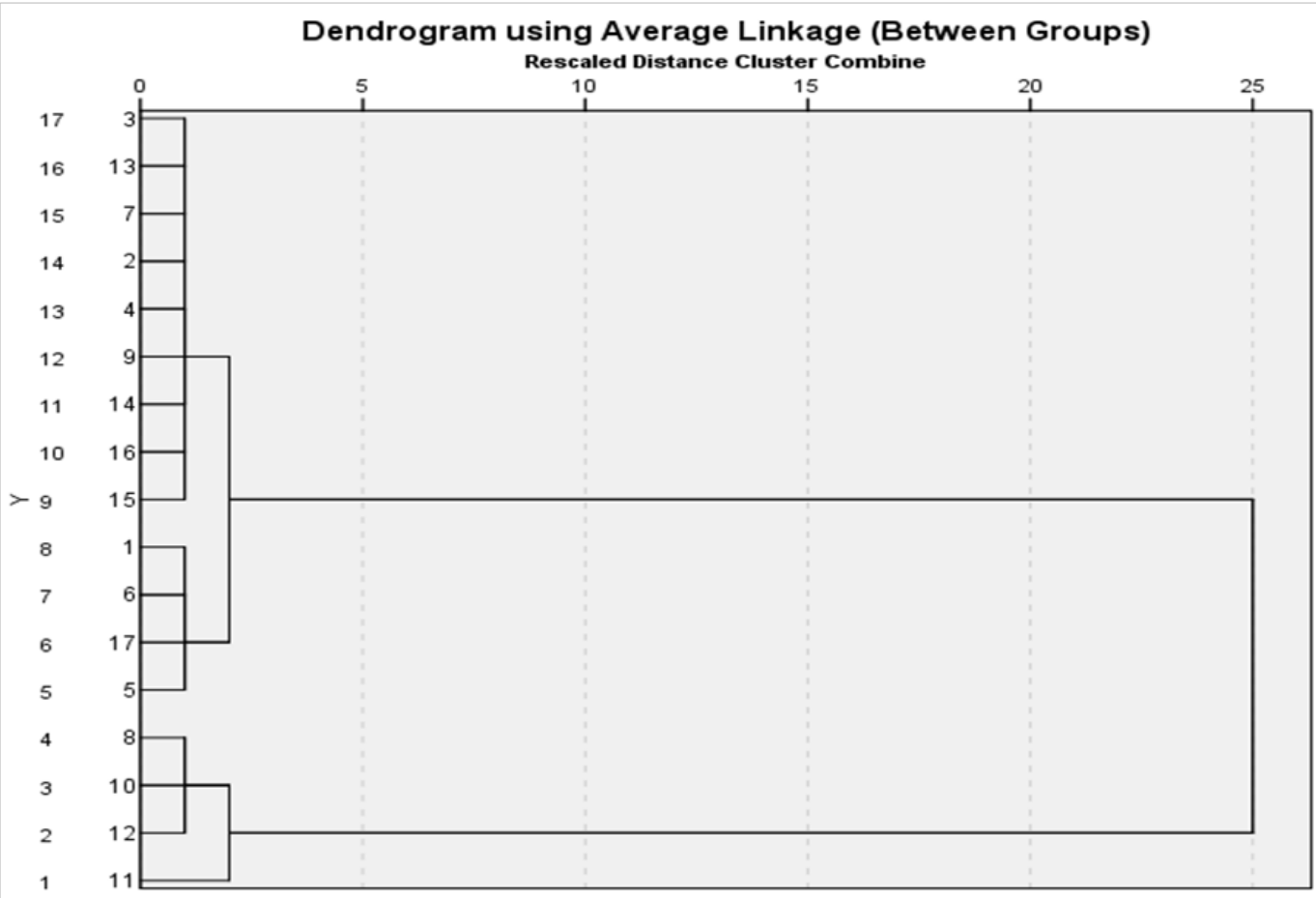

Figure 14. Dendrogram showing clustering of analysed zinc sampling sites

The second group to emerge consists of points S1, S6, $\mathrm{S} 5, \mathrm{~S} 16, \mathrm{~S} 14$ and S15.This is the mild cluster for copper air pollution. However for this group, all the other points seem to cluster in one group except for point S15 which seems to be in its own sub group of being on the high side of being mild.

The third cluster to emerge consists of points S3, S4, S7, $\mathrm{S} 13, \mathrm{~S} 9$ and $\mathrm{S} 2$. This cluster denotes the hot spots for $\mathrm{Cu}$. Further analysis of this cluster shows that the hot spots can further be categorized into 3 sub clusters. The first sub cluster consists of pointsS3, S4, S7 and S13. These are the hot spots on the lower side. The other sub cluster consists of point $\mathrm{S} 2$ which is a red hot spot but on the high side the last sub cluster consisted of the point S9 which is a hot spot somewhere in between. The third sub group consists of point S2 which is a high red hot spot.

\subsubsection{Lead Heavy Metal Air Pollution Clusters}

For $\mathrm{Pb}$ the first cluster to emerge consists of points $\mathrm{S} 4$, S16, S1, S3, S6, S7, S14 and S15. These are the cold spots for Lead. Like in all the other cases encountered before, this cluster can further sub be further sub divided into the low cold spots or the high cold spots. The high cold spots consists of points S7, S14 and S15 and the low cold spots consisted of points S4, S16, S1, S3 and S6. This lower cold spot cluster denotes the pristine region for Lead.

The second group consists of points S11, S12, S10, S5, $\mathrm{S} 17$, and $\mathrm{S} 8$. This is the mild cluster for $\mathrm{Pb}$ Lead air pollution. This cluster can be further sub divided into two groups, the high mild spot and the low mild spot. The high mild spots consist of points S5, S17, and S8. The low mild spot cluster consists of points $\mathrm{S} 11, \mathrm{~S} 12$ and $\mathrm{S} 10$.
The third group consists of points S9, S13 and S2. These are the hot spots for $\mathrm{Pb}$. These hot spots can further be split into two groups the lower side consisting of S9, S13 and S2 on the high side

\subsubsection{Zinc Heavy Metal Air Pollution Clusters}

For $\mathrm{Zn}$ the first of the two clusters that emerges consist of points S3, S13, S7, S2, S4, S9, S14, S16, S15, S1, S6, $\mathrm{S} 17$, and S5. This cluster denotes the polluted cluster. This cluster can be further sub divided into two sub groups. One group consists of points S3, S13, S7, S2, S4, S9, S14, S16, and $\mathrm{S} 15$ which can be noted as the hot spots and the other consists of points, S1, S6, S17, and S5 which can be described as the mild spots. The second cluster consists of points $\mathrm{S} 8, \mathrm{~S} 10, \mathrm{~S} 12$, and $\mathrm{S} 11$. These can be described as the unpolluted clusters.

Even though these clusters were successfully classified, looking back at the variance it shows that the RAFs of $\mathrm{Zn}$ do not vary that much throughout the study area. So theoretically the classes do exist as is shown by the SDM and the dendrogram but in practical terms, the differences are insignificant can just be considered as one class.

Table 5. Correlation coefficient ( $\mathrm{r}$ ) between element content in mosses derived from normalized (log transformed) data.

\begin{tabular}{|c|c|c|c|c|}
\hline & $\mathrm{Cr}$ & $\mathrm{Cu}$ & $\mathrm{Pb}$ & $\mathrm{Zn}$ \\
\hline $\mathrm{Cr}$ & 1.00 & & & \\
\hline $\mathrm{Cu}$ & 0.89 & 1.00 & & \\
\hline $\mathrm{Pb}$ & 0.79 & 0.87 & 1.00 & \\
\hline $\mathrm{Zn}$ & 0.80 & 0.91 & 0.90 & 1.00 \\
\hline
\end{tabular}

**. Correlation is significant at the 0.01 level (2-tailed). 


\subsection{Sources of the Heavy Metals}

The question of sources is of paramount importance in air pollution studies. This is because, once the source has been identified, appropriate measures can be taken so that the integrity of the environment within its footprint is preserved. From previous studies, by $[17,18]$ it can be noted that, the concentrations of air pollutants such as heavy metals; demonstrate steep concentration gradients from on source to near source micro environments. With that understanding, it was assumed that for heavy metal deposition from air, the sources would have to be somewhere close to the hot spots. So the search for the sources was conducted within and around the vicinities of the hotspots.

Correlation coefficients were used as the criteria for the determination of the number of sources to be considered. According to Sun, et al., [19] strong correlation coefficients between metals, indicate that they have the same source. Thus strong correlation coefficients would imply that, they have the same source and weak correlation coefficients would imply different sources. Since the data set for Zn was not normally distributed, all the data was normalized by $\log$ transforming it, so as to allow for comparison between metals. Table 5 shows a matrix of correlation coefficients for all the metals analyzed and it can be seen that they all had strong positive correlations. Hence the metals were assumed to be coming from the same source.

The SDM for the total heavy metals was used for this search for the source. Looking at the SDM for total heavy metal deposition (Figure 10) it can be seen that the hot spots occurred at points S2, S3, S4, S7, S9 and S13. By visual inspection, it can be noted that points $\mathrm{S} 2, \mathrm{~S} 3, \mathrm{~S} 4$, and S7 are either close to or within a car park. So the initial assumption was that these heavy metals were as a result of traffic related emissions. But this assumption could not explain points S9 and S13. On closer analysis of vicinities of points S9 and S13 it was realized that point S9 is close to the university's site and transport department which is a high traffic zone. The point S13 is adjacent to a City of Harare, major road junction between Churchill Avenue and College Rd. Thus the source of these heavy metals was found out to be traffic related emissions.

At crossroads, a pattern of braking and accelerating driving mode, so called "stop and go", is especially increased [20]. So this can explain why we have these car parks and cross roads as the source of Heavy metals. The exact sources of the heavy metals can be identified as follows:

Chromium: Fuel, lubricating oil and Brakes emissions [1][2][3].

Copper: Fuel, lubricating oil and Brakes emissions [1][2][3].

Lead: Lubricating oil and brakes emissions [2][3].

Zinc: Fuel, lubricating oil and Brakes emissions [1][2][3].

\section{Conclusions}

Moss, Grimmia dissimulate was successfully used as an active biomonitor for the assessment of heavy metal air pollution. After the exposure period, the order of heavy metal deposition was found to be as follows, $\mathrm{Cu}>\mathrm{Cr}>$ $\mathrm{Zn}>\mathrm{Pb}$. Out of the 4 metals studied, $\mathrm{Zn}$ was found to have deposited in a uniform fashion, throughout the study area. Application of cluster analysis revealed that, the distributions of $\mathrm{Cu}$ and $\mathrm{Cr}$ are very similar, while $\mathrm{Pb}$ and $\mathrm{Zn}$ each had their own different patterns though that of $\mathrm{Pb}$ showed some resemblance to that of $\mathrm{Cu}-\mathrm{Cr}$ than to $\mathrm{Zn}$.

The different zones of heavy metal depositions were successfully identified and their spatial extent mapped. The points S2, S3, S4, S7, S9 and S13, were identified as being the hotspots and points S1, S6, S14 and S15 as the mild spots while points S5, S17, S8, S10, S11 and S12 were the cold spots. The cause for the presence of these heavy metals was found to be mostly from vehicle related emissions.

\section{REFERENCES}

[1] WHO, Air quality guidelines for Europe, second ed., vol. No. 91, F. Theakston, Ed., Copenhagen: WHO regional publications, 2000.

[2] B. Smodiš and A. Bleise, "Biomonitoring of Atmospheric Pollution," in "Internationally harmonised approach to biomonitoring trace element atmospheric deposition" (with emphasis on trace elements) - BioMap II, 2000.

[3] World Health Organization, " Burden of Disease From Household Air Pollution for," World Health Organization, Geneva, Switzerland, , 2014.

[4] L. K. Boamponsem, J. I. Adam, S. B. Dampare, B. J. Nyarko and D. K. Essumang, "Assessment of atmospheric heavy metal deposition in the Tarkwa gold mining area of Ghana using epiphytic lichens," Nuclear Instruments and Methods in Physics Research, p. 1492-1501, 2010.

[5] K. J. Puckett, "Bryophytes and lichens as monitors of metal deposition.," Bibliotheca Lichenologica 30,, p. 231-267., 1988.

[6] P. C. Onianwa, "Monitoring Atmospheric Metal Pollution: A Review of the Use of Mosses as Indicators.," Environmental Monitoring and Assessment, vol. 70, no. 1, 2000.

[7] S. Dragovič and N. Mihailovič, "Analysis of Mosses and Topsoils for Detecting Sources of Heavy Metal Pollution: Multivariate and Enrichment Factor Analysis.," Environmental Monitoring and Assessment, Vol.157, No.1-4,, pp. 383-390, 2009.

[8] D. Schwela, "Review of Urban Air Quality in Sub-Saharan Africa Region - Air Quality profile of Sub-Saharan Africa countries," in Better Air Quality in Sub-Saharan Africa (BAQ-SSA), Nairobi, 2006. 
[9] S. Feresu, "An Air Pollution Information Network for Africa Perspective on Air Pollution and Climate Change," 15th IUAPPA World Clean Air Congress , Vancouver, 2010.

[10] ICP Vegetation, "Heavy metals in European mosses: 2005/2006 survey. Monitoring manual.," ICP Vegetation Programme Coordination Centre, CEH Bangor, UK, 2005.

[11] A. Ares, J. Aboal, A. Carballeira, S. Giordano, P. Adamo and J. Fernández, "Moss bag biomonitoring: A methodological review," Science of the Total Environment 432, p. 143-158, 2012.

[12] L. Barandovski, M. Frontasyeva, T. Stafilov, R. Šajn and T. Ostrovnaya, "Multi-element atmospheric deposition in Macedonia studied by the moss biomonitoring technique," Environmental Science and Pollution Research ; June 2015.

[13] R. D. Beaty and J. D. Kerber, Concepts, Instrumentation and Techniques in Atomic Absorption Spectrophotometry, THE PERKIN-ELMER CORPORATION, 1993.

[14] K. Shakya, M. K. Chettri and T. Sawidis, "Impact of Heavy Metals (Copper, Zinc, and lead) on the chlorophyll content of some mosses.," Arch Environ Contam Toxicol, 2008.

[15] J. Hauke and T. Kossowski, "Comparison Of Values Of Pearson's And Spearman's Correlation Coefficients On The Same Sets Of Data," QUAESTIONES GEOGRAPHICAE 30(2) , p. 87-93, 2011

[16] G. A. Baker, Transformation of non-normal frequency distributions into normal distributions. Annals of Mathematical Statistics, Vols. 5, 1934.
[17] G. Hagler, R. Baldauf, E. Thoma, T. Long, R. Snow, J. Kinsey, L. Oudejans and B. Gullett, "Ultrafine particles near a major roadway in Raleigh, north Carolina: downwind attenuation and correlation with traffic-related pollutants.," Atmos. Environ. 43, p. 1229-1234., 2009.

[18] A. Karner, D. Eisinger and D. Niemeier, "Near-roadway air quality: synthesizing the findings from real-world data.," Environ. Sci. Technol. 44, p. 5334-5344, 2010.

[19] H. Sun, J. Li and X. Mao, "Heavy Metals' Spatial Distribution Characteristics in a Copper Mining Area of Zhejiang Province," Journal of Geographic Information System, pp. 46-54, 2012.

[20] J. H. Tsai , H. L. Chiang, Y. C. Hsu, H. C. Weng and C. Y. Yang, "The speciation of volatile organic compounds (VOCs) from motorcycle engine exhaust at different driving modes," Atmospheric Environment 37, p. 2485-2496, 2003.

[21] EMEP/EEA, EMEP/EEA air pollutant emission inventory guidebook. Passenger cars, light commercial trucks, heavy-duty vehicles including buses and motor cycles, Copenhagen: EMEP/EEA, 2013.

[22] T. Pulles, H. Denier van der Gon, W. Appelman and M. Verheul, "Emission factors for heavy metals from diesel and petrol used in European vehicles," Atmospheric Environment, vol. 61, pp. 641-651, 2012.

[23] A. Thorpe and R. Harrison, "Sources and properties of non-exhaust particulate matter from road traffic: A review, Science," Total Environment, vol. 400, p. 270-282, 2008. 